\title{
Некоторые аспекты субъективной детерминации здоровья представителей старших возрастных групп
}

\author{
Колпина Л.В., Бояринова И.В., Вангородская С.А. \\ Белгородский государственный национальный исследовательский университет, \\ Россия, 308015, г. Белгород, ул. Победы, 85 \\ E-mail: karlkastane@yandex.ru, boyarinova@bsu.edu.ru, Vangorodskaya@bsu.edu.ru
}

\begin{abstract}
Аннотация. Трансформация возрастной структуры, имеющая своим результатом увеличение доли пожилых людей в населении, диктует необходимость привлечения внимания научного сообщества к изучению условий и факторов, призванных обеспечить поддержание оптимальных параметров физического, социального и эмоционального благополучия населения старших возрастных групп. Целью данной статьи является анализ влияния на самочувствие представителей старших возрастных групп фактора планирования жизни. На основе данных репрезентативного социологического опроса доказано, что наиболее высокими показателями самооценки здоровья обладают представители старших возрастных групп с горизонтом планирования пять лет и более, планировавшие свою жизнь в пожилом возрасте задолго до его наступления, а также убежденные в том, что здоровье и продолжительность жизни в существенной мере зависят от усилий самого человека. Показано отрицательное влияние негативизации образа старости на самосохранительные установки и поведение в целом. Результаты исследования имеют важное теоретическое и прикладное значение, поскольку способствует развенчанию негативных геронтологических стереотипов и призвано инициировать разработку и внедрение мер, направленных на стимулирование у пожилых людей практик долгосрочного планирования собственной жизни.
\end{abstract}

Ключевые слова: негативные геронтостереотипы, локус контроля, пожилые люди, планирование жизни, показатель самооценки здоровья, факторы здоровья и продолжительности жизни.

Благодарности: Статья подготовлена при поддержке гранта РФФИ 19-011-00661 «Влияние эйджистских стереотипов на формирование самоограничительных установок и практик граждан старшего поколения».

Для цитирования: Колпина Л.В., Бояринова И.В., Вангородская С.А. 2020. Некоторые аспекты субъективной детерминации здоровья представителей старших возрастных групп. NOMOTHETIKA: Философия. Социология. Право. 45 (4): 644-654. DOI 10.18413/2712-746X-202045-4-644-654

\section{Some aspects of subjective determination of the healt of older age groups}

\author{
Lola V. Kolpina, Irina V. Boyarinova, Svetlana A. Vangorodskaya \\ Belgorod National Research University, \\ 85 Pobeda St, Belgorod, 308015, Russia \\ E-mail: karlkastane@yandex.ru, boyarinova@bsu.edu.ru, Vangorodskaya@bsu.edu.ru
}

\begin{abstract}
The transformation of the age structure characteristic of the fourth phase of the "classical" demographic transition, which results in an increase in the share of older people in the population, dictates the need to attract increased attention of the scientific community to the study of conditions and factors designed to ensure the maintenance of optimal parameters of physical, social and emotional wellbeing of the population of older age groups. The purpose of this article is to analyze the impact on the
\end{abstract}


well-being of older age groups of the life planning factor, represented in the study by two options: 1) planning of life in old age, carried out earlier, long before its onset, and 2) actual life planning, carried out by representatives of older age groups who are at this age segment. Based on data from a representative sociological survey conducted in 2019 among the population of older age groups in the Belgorod and Voronezh regions, it is proved that the highest indicators of self-assessment of health are representatives of older age groups with a planning horizon of five years or more, who planned their life in old age long before it occurred, and are also convinced that health and life expectancy significantly depend on the efforts of the individual. The negative impact of negation of the image of old age on selfpreservation attitudes and behavior in General is shown. Consideration of this problem is of great theoretical and applied importance, since it helps to debunk negative gerontological stereotypes and is intended to initiate the development and implementation of measures aimed at stimulating the practice of long-term planning of their own lives in older people.

Keywords: negative gerontostereotypes, locus of control, elderly people, life planning, health selfassessment indicator, health factors and life expectancy.

Acknowledgements: The article was prepared with the support of the RFBR grant 19-011-00661 "The Influence of ageist stereotypes on the formation of self-limiting attitudes and practices of older citizens".

For citation: Kolpina L.V., Boyarinova I.V., Vangorodskaya S.A. 2020. Some aspects of subjective determination of the health of older age groups. NOMOTHETIKA: Philosophy. Sociology. Law series. 45 (4): 644-654 (in Russian). DOI 10.18413/2712-746X-2020-45-4-644-654

\section{Введение}

Проблема субъективной детерминации здоровья своими корнями уходит в проблему здоровьесбережения - личностных факторов, обуславливающих укрепление или разрушение здоровья [Вангородская, 2018]. Отношение к здоровью складывается под совокупным воздействием глобальных и локальных факторов, опосредующих специфику здоровьесберегающего поведения как на индивидуальном, так и на популяционном уровнях. При этом, по словам А.Г. Вишневского, «все факторы не просто существуют параллельно, а теснейшим образом взаимосвязаны, изменение одного сразу же меняет и все остальные, и образуется новый, непредсказуемый, как в калейдоскопе, узор» [Вишневский, 2015, с. 15].

Детерминация здоровья в современном обществе имеет свою специфику, обусловленную, в первую очередь, отсутствием «территориальных, временных или социальных границ, которые могли бы служить преградой современных опасностей» [Субетто, 2018, c. 70]. Наглядным примером может служить охватившая мир в 2020 году эпидемия (пандемия) коронавируса, заставившая переосмыслить как значимость индивидуальных усилий, так и эффективность государственных систем охраны здоровья населения.

Трансформация возрастной структуры, характерная для четвертой фазы «классического» демографического перехода [Реэр, 2014, Клупт, 2010] и имеющая своим результатом увеличение доли пожилых людей в населении, актуализирует проблему не столько увеличения продолжительности индивидуальной жизни, сколько адаптации общества в целом и населения старших возрастных групп в частности к происходящим изменениям, а также создания условий для поддержания активного долголетия, характеризующегося оптимальными параметрами физического, социального и эмоционального благополучия [Барсуков, 2016].

В отношении пожилых людей проблема детерминации здоровья имеет свои особенности [Allen, 2016; Morganroth, 2017, Барсуков, 2016], предопределенные, в частности, распространенностью в общественном сознании негативных стереотипов относительно старости и пожилого возраста (геронтостереотипов) [Butler, 1969; Балабанова, 2017; Микляева, 2014; Смирнова, 2008], которые, усваиваясь пожилыми людьми, прямо или косвенно негативно влияют на их здоровье [Колпина и др., 2015]. 
Например, исследования показывают прямую зависимость между наличием у пожилых людей негативных геронтостереотипов и отрицательной динамикой когнитивных, моторных и физиологических функций, ухудшением показателей самооценки здоровья [Nelson, 2016; Ouchida, Lachs, 2015]. В свою очередь, положительное отношение к своему возрасту и к сопряженной с ним ситуации прямо коррелирует с улучшением функционального здоровья людей данной возрастной группы. В частности, пожилые люди с позитивными геронтостереотипами на $44 \%$ чаще полностью оправляются от тяжелой инвалидности, чем с негативными [Levenson, 1981; Levy et al., 2015;], и продолжительность жизни у таких людей на 7,5 лет дольше [Levy et al., 2015; Robbins, 2015; Колпина, Реутов, 2019].

Одной из причин снижения здоровья у пожилых людей является их отказ от здоровьесберегающих практик, обусловленный интериоризацией (усвоением) распространенного в общественном сознании стереотипа о том, что старость и болезни неразделимы; болезни также неизбежны, как и старость, а потому нет смысла уделять внимание своему здоровью [Колпина и др., 2015]. Так, граждане старшего поколения, убежденные в том, что усталость, подавленное настроение, зависимость от других и снижение либидо являются нормальной частью старения, реже считают необходимым обращаться за медицинской помощью [Ouchida, Lachs, 2015], они менее склонны к физической активности, различным профилактическим мерам, как, например, регулярное медицинское обследование, сбалансированная диета, использование ремней безопасности, ограничение употребления алкоголя и табака ]Levy and Meyers, 2006; Ouchida, Lachs, 2015 ].

Вместе с тем в настоящее время практически отсутствуют теоретические исследования, обобщающие и систематизирующие основные аспекты субъективной детерминации здоровья в отношении пожилых людей, обусловленные распространенностью в общественном сознании негативных стереотипов относительно старости и пожилого возраста, а также раскрывающие их методологические особенности. Исходя из этого, целью данной статьи является анализ влияния фактора планирования жизни на самочувствие представителей старших возрастных групп. В нашем исследовании этот фактор представлен двумя опциями: 1) планирование жизни в пожилом возрасте, осуществлявшееся ранее, задолго до его наступления и 2) актуальное планирование жизни, осуществляемое представителями старших возрастных групп, находящимися на данном возрастном отрезке.

\section{Эмпирическая база и методы исследования}

Эмпирической базой исследования являются результаты социологического исследования «Влияние эйджистских стереотипов на формирование самоограничительных установок и практик граждан старшего поколения», проведенного в 2019 году. В качестве основного метода сбора первичной социологической информации использовался массовый анкетный опрос по репрезентативной региональной выборке, включающей в себя население Белгородской и Воронежской областей $(\mathrm{N}=800)$. Группа пожилых людей стратифицирована по возрасту: 60-64 года $(24,8$ \%), 65-69 лет $(30,4 \%), 70-74$ года $(21,4$ \%), 75-79 лет (16,1\%), 80 лет и старше (7,3\%), полу (35,7 \% мужчин и 64,3 \% женщин и территориальному признаку: 61,8 \% респондентов проживает в городских поселениях, 38,2 \% - в сельских).

В основу социологического анализа полученной информации легла группировка данных в зависимости от основных социально-демографических и мировоззренческих характеристик респондентов (территория проживания, пол, возраст, образование, стаж работы). Для изучения связи между теми или иными негативными геронтостереотипами и установками и практиками использовался анализ таблиц сопряженности; для характеристики выборочной интериоризации негативных геронтостереотипов - метод ранжирования данных.

Результаты проведенного нами социологического опроса населения в возрасте 60 лет и старше показали, что геронтостереотип о взаимосвязи старости и болезней разде- 
ляют 54,9 \% старшей возрастной группы, что, естественно, является негативным прогностическим маркером с точки зрения реализации ими здоровьесберегающих практик.

\section{Основные результаты и их обсуждение}

Анализ степени влияния на самочувствие пожилых людей их жизненного планирования в «допожилом» возрасте мы осуществили на основе анализа сопряженности ответов респондентов на вопросы: «В молодом и зрелом возрасте строили ли Вы планы относительно своей жизни в пожилом возрасте?» и «Как Вы оцениваете состояние своего здоровья?» (табл. 1).

Сравнение показателей текущей самооценки здоровья и планирования жизни на предыдущих возрастных этапах показало, что у тех респондентов, которые ранее имели достаточно четкие планы на этот жизненный период, положительные самооценки здоровья (в разной степени) превалируют над отрицательными. И наоборот, чем в меньшей степени осуществлялось планирование, тем больше на момент проведения исследования отрицательная самооценка здоровья превалирует над положительной.

Таблица 1

Table 1

Сопряженность показателей текущей самооценки здоровья и планирования жизни на предыдущих возрастных этапах представителей старших возрастных групп (\%)

Correlation of indicators of current self-assessment of health and life planning at previous age stages of representatives of older age groups (\%)

\begin{tabular}{|c|c|c|c|c|c|}
\hline \multirow[b]{2}{*}{$\begin{array}{l}\text { В молодом и } \\
\text { зрелом воз- } \\
\text { расте строили } \\
\text { ли Вы планы } \\
\text { относительно } \\
\text { своей жизни в } \\
\text { пожилом воз- } \\
\text { расте? }\end{array}$} & \multicolumn{5}{|c|}{ Как вы оцениваете состояние своего здоровья? } \\
\hline & $\begin{array}{l}\text { Хорошее: не } \\
\text { болею или бо- } \\
\text { лею очень ред- } \\
\text { ко, обычно хо- } \\
\text { рошо себя чув- } \\
\text { ствую }\end{array}$ & $\begin{array}{l}\text { Удовлетвори- } \\
\text { тельное: иногда } \\
\text { болею или чув- } \\
\text { ствую себя не- } \\
\text { здоровым }\end{array}$ & $\begin{array}{l}\text { Среднее (до- } \\
\text { вольно часто } \\
\text { болею или } \\
\text { чувствую се- } \\
\text { бя нездоро- } \\
\text { вым }\end{array}$ & $\begin{array}{l}\text { Плохое (есть } \\
\text { хронические } \\
\text { заболевания, } \\
\text { постоянно } \\
\text { плохо себя } \\
\text { чувствую) }\end{array}$ & $\begin{array}{l}\text { Затруд- } \\
\text { няюсь } \\
\text { отве- } \\
\text { тить }\end{array}$ \\
\hline $\begin{array}{l}\text { Да, довольно } \\
\text { четкие. }\end{array}$ & 14,5 & 36,8 & 31,6 & 46,1 & 2,6 \\
\hline $\begin{array}{l}\text { Примерно } \\
\text { представлял, } \\
\text { как буду про- } \\
\text { водить это } \\
\text { время. }\end{array}$ & 8,5 & 39,7 & 38,2 & 50,9 & 0,9 \\
\hline $\begin{array}{l}\text { Не строил ни- } \\
\text { каких планов, } \\
\text { даже не заду- } \\
\text { мывался об } \\
\text { этом }\end{array}$ & 6,7 & 38,0 & 32,3 & 51,3 & 4,0 \\
\hline $\begin{array}{l}\text { Затрудняюсь } \\
\text { ответить }\end{array}$ & 6,4 & 34,0 & 26,6 & 49,3 & 6,4 \\
\hline
\end{tabular}

Сравнение показателей самооценки здоровья пожилых людей по параметру их актуального горизонта планирования позволяет увидеть следующее: принципиально чаще других характеризуют свое здоровье как хорошее те, кто планирует свою жизнь на 5-10 лет вперед $(18,5 \%)$, а реже - те, кто не строит планов, живет одним днем (4,1 \%). И напротив, реже других оценивают свое здоровье как плохое те, кто имеют максимальный горизонт планирования - 5-10 лет (5,6 \%), а чаще - кто не планирует свою жизнь вообще $(24,1 \%)$ и те, кто планирует менее, чем на год $(25,0 \%)$ (табл. 2). 
Таким образом, аналогично тенденции, выявленной при ответах на предыдущий вопрос, в данном случае также можно говорить о прямой корреляции между увеличением горизонта планирования и повышением самооценки здоровья. И наоборот - в группах опрошенных с горизонтом планирования менее двух лет или не планирующих свою жизнь вовсе, наблюдается существенное превалирование в разной степени отрицательных самооценок здоровья над положительными.

Таблица 2

Table 2

Сопряженность показателей актуального планирования жизни и самооценки здоровья представителей старших возрастных групп (\%)

Correlation of indicators of actual life planning and self-assessment of health of older age groups $(\%)$

\begin{tabular}{|l|c|c|c|c|c|}
\hline \multirow{2}{*}{$\begin{array}{c}\text { На какой } \\
\text { период Вы } \\
\text { сейчас стро- } \\
\text { ите свои } \\
\text { жизненные } \\
\text { планы }\end{array}$} & $\begin{array}{c}\text { Хорошее } \\
\text { (не болею } \\
\text { / болею } \\
\text { редко) }\end{array}$ & $\begin{array}{c}\text { Удовлетворительное } \\
\text { (иногда болею или } \\
\text { чувствую себя не- } \\
\text { здоровым }\end{array}$ & $\begin{array}{c}\text { Среднее (ча- } \\
\text { сто болею } \\
\text { или чув- } \\
\text { ствую себя } \\
\text { нездоровым) }\end{array}$ & $\begin{array}{c}\text { Плохое (есть } \\
\text { хронические } \\
\text { заболевания, } \\
\text { постоянно } \\
\text { плохо себя } \\
\text { чувствую) }\end{array}$ & $\begin{array}{c}\text { Затрудняюсь } \\
\text { ответить }\end{array}$ \\
\hline На 5-10 лет & 18,5 & 44,4 & 30,6 & 5,6 & 0,9 \\
\hline На 3-4 года & 7,8 & 41,6 & 38,0 & 11,4 & 1,2 \\
\hline На 1-2 года & 5,9 & 33,6 & 40,8 & 15,8 & 3,9 \\
\hline $\begin{array}{l}\text { Менее чем } \\
\text { на год }\end{array}$ & 6,5 & 35,5 & 29,8 & 25,0 & 3,2 \\
\hline $\begin{array}{l}\text { Не строю } \\
\text { планов, } \\
\text { живу одним } \\
\text { днем }\end{array}$ & 4,1 & 36,5 & 31,2 & 24,1 & 4,1 \\
\hline $\begin{array}{l}\text { Затрудняюсь } \\
\text { ответить }\end{array}$ & 10,0 & 38,8 & 30,0 & 17,5 & 3,7 \\
\hline
\end{tabular}

Учитывая доказанную многими исследованиями роль интернального локуса контроля в формировании здоровьесберегающего поведения, мы предположили, что по мере увеличения горизонта планирования (который, по идее, коррелирует с убежденностью о подконтрольности субъекту ситуации на разных жизненных этапах и маркирует наличие у него интернального локуса контроля), должна расти доля респондентов, считающих, что более всего здоровье зависит от собственных усилий человека.

Для проверки этого предположения респондентам был предложен перечень факторов (наследственность, усилия человека по сохранению и укреплению здоровья, психическое и эмоциональное состояние человека, окружающая среда, качество и доступность здравоохранения, социальной защиты и поддержки), от которых, по их мнению, в наибольшей степени зависит здоровье человека.

Отметим, что четкой зависимости между оценкой факторов здоровья и самооценкой здоровья выявлено не было. В то же время по двум факторам (собственные усилия и доступность и качество социальной защиты) можно увидеть некоторые тренды, касающиеся экстернального и интернального локуса контроля. Так, на порядок реже других выбирали вариант ответа «здоровье зависит от собственных усилий» те, кто не планирует свою жизнь, живут одним днем (37,6 \% против 45-52 \% в других группах). И они же чаще всего в качестве первоочередного фактора здоровья назвали качество и доступность услуг сферы здравоохранения, социальной защиты и поддержки (экстернальный локус контроля) (46,5 \% против 35,2 \% 
ответивших так же в группе с горизонтом планирования 5-10 лет; в других группах соответствующий тренд не регистрируется). То есть, с одной стороны, четких корреляций между изменением горизонта планирования и локуса контроля в отношении здоровья в рамках нашего исследования не зафиксировано. С другой - можно говорить о наблюдаемой в рамках исследования зависимости между долгосрочным планированием и предпочтением личных усилий в качестве основной детерминанты индивидуального здоровья.

В вопросе о факторах продолжительности жизни (который можно рассматривать как производную вопроса о факторах здоровья) статистическая связь между локусом контроля и оценками самочувствия более заметна, чем в вопросе о факторах здоровья (табл. 3). Так, самые высокие значения ответа о первостепенной роли усилий человека в достижении продолжительной жизни (интернальный локус контроля) представлены в группах опрошенных с высокими и умеренными самооценками здоровья (60 и 49,5 \% соответственно), а самые низкие - в группах, характеризующихся низкими его самооценками (среднее - 39,7 \%, плохое - 40,7\%).

Таблица 3

Table 3

Сопряженность показателей самооценки здоровья и представлений о факторах продолжительности жизни в старших возрастных группах (\%)

Correlation of indicators of self-assessment of health and ideas about factors of life expectancy in older age groups (\%)

\begin{tabular}{|c|c|c|c|c|c|}
\hline \multirow[b]{2}{*}{$\begin{array}{c}\text { Как Вы оцениваете } \\
\text { состояние своего } \\
\text { здоровья? }\end{array}$} & \multicolumn{5}{|c|}{$\begin{array}{c}\text { По Вашему мнению, от чего, в первую очередь, зависит продолжительность } \\
\text { жизни человека? (выберите не более двух ответов) }\end{array}$} \\
\hline & $\begin{array}{l}\text { Наследствен- } \\
\text { ность }\end{array}$ & $\begin{array}{l}\text { Свои } \\
\text { уси- } \\
\text { лия }\end{array}$ & $\begin{array}{c}\text { Психическое } \\
\text { и эмоцио- } \\
\text { нальное } \\
\text { состояние }\end{array}$ & $\begin{array}{l}\text { Окружаю- } \\
\text { щая среда }\end{array}$ & $\begin{array}{c}\text { Качество и до- } \\
\text { ступность услуг } \\
\text { здравоохране- } \\
\text { ния и социаль- } \\
\text { ной защиты }\end{array}$ \\
\hline $\begin{array}{l}\text { Хорошее (не болею } \\
\text { / болею редко, } \\
\text { обычно хорошо } \\
\text { себя чувствую) }\end{array}$ & 33,8 & 60,0 & 18,5 & 35,4 & 26,2 \\
\hline $\begin{array}{l}\text { Удовлетворитель- } \\
\text { ное (иногда болею } \\
\text { или чувствую себя } \\
\text { нездоровым }\end{array}$ & 33,1 & 49,5 & 30,8 & 30,5 & 35,4 \\
\hline $\begin{array}{l}\text { Среднее (часто бо- } \\
\text { лею или чувствую } \\
\text { себя нездоровым }\end{array}$ & 31,6 & 39,7 & 23,5 & 38,2 & 47,4 \\
\hline $\begin{array}{l}\text { Плохое: (есть хро- } \\
\text { нические заболева- } \\
\text { ния, постоянно } \\
\text { плохо себя } \\
\text { чувствую) }\end{array}$ & 24,4 & 40,7 & 24,4 & 30,4 & 47,4 \\
\hline $\begin{array}{l}\text { Затрудняюсь } \\
\text { ответить }\end{array}$ & 30,4 & 30,4 & 17,4 & 8,7 & 69,6 \\
\hline
\end{tabular}

Обратная ситуация наблюдается по ответам, характеризующим экстернальный локус контроля, где фактором продолжительности жизни выступает качество и доступность здравоохранения, социальной защиты. В группах, характеризующихся наиболее низкими показателями самооценки здоровья, этот вариант ответа отметили по 47,4 \% опрошенных, а наиболее высокими - на порядок меньше: 35,4 \% (удовлетворительное) и 26,2 \% (хорошее). 
Можно предположить, что, те, у кого хорошее здоровье, в силу более низкой зависимости от системы здравоохранения повышают значимость собственных усилий и снижают важность этого института, а имеющие плохое здоровье - наоборот. Так, локус контроля в двух группах с наиболее высокими показателями самооценки здоровья имеет более выраженную интернальную направленность (превалируют ответы о значимости собственных усилий человека), а в двух группах с низкими самооценками здоровья - экстернальную (превалируют ответы о первостепенной значимости системы здравоохранения и социальной защиты).

Интересно отметить, что оценивающие свое здоровье как в разной степени плохое в большинстве случаев считают все факторы, кроме системы здравоохранения и социальной защиты, менее значимыми (в сравнении с теми, кто оценивает свое здоровье как в разной степени хорошее).

Так, 24,4 \% из числа тех, кто считает свое здоровье плохим (против 32-34 \% в других группах) в качестве наиболее значимого фактора долголетия называют наследственность. Представители этой группы наравне с теми, кто считает свое здоровье удовлетворительным, реже остальных называют в качестве наиболее важного фактора окружающую среду (примерно по 30 \% против 35-38 \% в других группах). Исключение составляет фактор психоэмоционального состояния, где лидирует группа с удовлетворительной самооценкой здоровья, тогда как в остальных группах значения ответов отличаются незначительно. Таким образом, учитывая указанные тенденции, считаем правомерным говорить о взаимосвязи между состоянием здоровья и локусом контроля человека.

Подтверждением значимости интернального локуса контроля в поддержании здоровья, по-видимому, можно считать результаты ответа на следующий вопрос: «Иногда пожилые люди перестают прикладывать усилия к поддержанию своего здоровья, ведению здорового образа жизни, не выполняют в точности предписания врача, объясняя это тем, что недомогания - признанная часть старения, а старость не остановить, а значит, такие усилия бессмысленны. Случалось ли с Вами такое?» (табл. 4).

Таблица 4

Table 4

Сопряженность показателей самооценки здоровья и самоограничительных практик в отношении здоровьесбережения в старших возрастных группах (\%)

Correlation of indicators of self-assessment of health and self-limiting practices in relation

to health saving in older age groups (\%)

\begin{tabular}{|c|c|c|c|c|c|}
\hline \multirow[b]{2}{*}{$\begin{array}{l}\text { Иногда пожилые } \\
\text { люди перестают } \\
\text { следить за своим } \\
\text { здоровьем... } \\
\text { Случалось ли } \\
\text { такое с Вами? }\end{array}$} & \multicolumn{5}{|c|}{ Как Вы оцениваете состояние своего здоровья? } \\
\hline & $\begin{array}{c}\text { Хорошее (не } \\
\text { болею / бо- } \\
\text { лею редко, } \\
\text { обычно хо- } \\
\text { рошо себя } \\
\text { чувствую) }\end{array}$ & $\begin{array}{l}\text { Удовлетвори- } \\
\text { тельное (ино- } \\
\text { гда чувствую } \\
\text { себя нездоро- } \\
\text { вым / болею ) }\end{array}$ & $\begin{array}{c}\text { Среднее (ча- } \\
\text { сто болею / } \\
\text { чувствую } \\
\text { себя нездо- } \\
\text { ровым) }\end{array}$ & $\begin{array}{c}\text { Плохое (есть } \\
\text { хронические } \\
\text { заболевания, } \\
\text { постоянно } \\
\text { плохо себя } \\
\text { чувствую) }\end{array}$ & $\begin{array}{c}\text { Затрудняюсь } \\
\text { ответить }\end{array}$ \\
\hline Да & 3,9 & 33,3 & 37,6 & 22,3 & 2,8 \\
\hline Нет & 10,8 & 43,3 & 30,9 & 12,7 & 2,3 \\
\hline $\begin{array}{l}\text { Затрудняюсь } \\
\text { ответить }\end{array}$ & 8,3 & 27,4 & 38,1 & 20,2 & 6,0 \\
\hline
\end{tabular}

Если высчитать разницу между суммами ответов представителей групп в разной степени с хорошим и в разной степени с плохим здоровьем и сравнить полученные значе- 
ния по группам согласившихся и не согласившихся с этим утверждением, то мы увидим следующее. В группе согласившихся с тем, что порой они перестают прикладывать усилия к собственному здоровьесбережению, находятся преимущественно представители двух групп с наиболее низкими показателями самооценки здоровья. Среди тех, кто не прекращает прикладывать усилия к сохранению своего здоровья, отмечается превалирование представителей двух групп с наиболее высокими показателями самооценки здоровья.

\section{Заключение}

На самочувствие представителей старшей возрастной группы, а значит, с высокой долей вероятности и на их здоровье влияет ряд субъективных детерминант. В их числе значительную роль играет планирование жизни, осуществляемое как задолго до наступления пожилого возраста, так и непосредственно в этом возрастном периоде. Результаты проведенного нами исследования показали, что те представители старших возрастных групп, которые ранее планировали свою «пожилую» жизнь, как и те, кто продолжает практику планирования на период 5 лет и более, характеризуются принципиально более высокими оценками своего здоровья, чем те, кто не планировал либо планирует ее на меньшие отрезки времени.

Указанные выводы объясняются тем, что величина горизонта планирования коррелирует с внутренним локусом контроля, при котором (и это также нашло подтверждение в рамках нашего исследования) здоровье человека рассматривается преимущественно как результат собственных усилий, и, следовательно, влечет за собой соответствующие действия. Об этом же свидетельствует статистически значимая связь между степенью выраженности внутреннего локуса контроля и представлениями о факторах продолжительности жизни. В качестве важного наблюдения можно отметить, что внешней локус контроля в отношении здоровья и продолжительности жизни у пожилых людей более всего сопряжен с ориентацией на доминирование системы здравоохранения и социальной защиты в качестве ключевых факторов продолжительности жизни, что можно трактовать, в том числе, как негативное влияние медикализма на здоровьесберегающие установки и практики.

Поскольку самосохранительное поведение строится на представлении о подконтрольности для человека ситуации в сфере здоровья, в этой связи негативным прогностическим маркером является наличие у пожилых людей установки на старость как на неизбежное дряхление и ухудшение здоровья. Среди тех, кто убежден, что старость - это всегда болезни, и в связи с этим отказывается от здоровьесберегающих практик, значительно чаще встречаются люди с низкими показателями самооценки здоровья, чем среди тех, кто не подвержен этому стереотипу.

Полученные результаты исследования имеют не только теоретическое, но и прикладное значение, поскольку, во-первых, вносят вклад в углубление теории социальной эксклюзии и социологии возраста посредством расширения представлений о механизмах интериоризации негативных геронтологических стереотипов и их влиянии на практики жизнедеятельности лиц старших возрастных групп, а, во-вторых, призваны инициировать разработку и внедрение комплекса мероприятий, направленных на стимулирование у пожилых людей практик долгосрочного планирования собственной жизни.

\section{Список литературы}

1. Балабанова К.А. Ковалева Г.А. 2017. Эйджизм как отражение отношения к пожилым людям в современном обществе: постановка проблемы. В кн.: Череповецкие научные чтения 2016. Материалы Всероссийской научно-практической конференции. 16-17 ноября 2016 г., Череповец, 1: 11-13. 
2. Барсуков В.Н. 2016. Старение населения в контексте концепции демографического перехода. Вопросы территориального развития. 1 (31): 3

3. Вангородская С.А. 2018. Факторы самосохранительного поведения населения региона (по результатам социологических исследований). Научный результат. Социология и управление. 4 (2): 13-26. DOI: 10.18413/2408-9338-2018-4-2-0-2

4. Вишневский А.Г. 2015. Время демографических перемен: избранные статьи. М., Изд. дом Высшей школы экономики, $517 \mathrm{c}$.

5. Клупт М.А. 2010. Демографическая повестка XXI века: теории и реалии. Социологические исследования, 8 (316): 60-71.

6. Колпина Л.В., Иванов С.В., Курдяев С.М., Щитикова О.Б. 2015. Эйджизм в восприятии пожилых людей и его влияние на социальное здоровье населения пожилого и старческого возраста. Вестник Всероссийского общества специалистов по медико-социальной экспертизе, реабилитации и реабилитационной индустрии, 4: 74-81.

7. Колпина Л.В., Реутов Е.В. 2019. Влияние эйджистских стереотипов на формирование самоограничительных практик граждан старшего поколения. Среднерусский вестник общественных наук, 14(2): 32-45. DOI: 10.22394/2071-2367-2019-14-2-32-45

8. Колпина Л.В., Реутова М.Н. 2019. Теоретические аспекты исследования механизма избирательной интериоризации негативных геронтостереотипов населением старших возрастных групп. Социальная компетентность, 4 (2):153-161.

9. Микляева А.В. 2014. Содержание возрастных стереотипов: эмпирическая типология. Письма в Эмиссия. Оффлайн, 2: 2148 URL: http://www.emissia.org/offline /2014/2148.htm (дата обращения: 09.09. 2020).

10. Реэр Д. 2014. Экономические и социальные последствия демографического перехода. Демографическое обозрение, 1(4): 41-67. URL: https://demreview.hse.ru/issue/view/154/156 (дата обращения: 09.09. 2020).

11. Смирнова Т.В. 2008. Пожилые люди: стереотипный образ и социальная дистанция. Социологические исследования, 8(292): 49-55.

12. Субетто А.И. 2018. Ноосферная парадигма стратегии восходящего воспроизводства населения России. Уровень жизни регионов России. 1(207): 77-94. DOI: https://doi.org/10.24411/1999-9836-2018-10009 $610-614$.

13. Allen J.O. 2016. Ageism as a risk factor for chronic disease. The Gerontologist, 56(4):

14. Butler R.N. 1969. Age-ism: Another form of bigotry. The Gerontologist, 9: 243-246

15. Levenson A.J. 1981. Ageism: A major deterrent to the introduction of curricula in aging. Gerontology and Geriatrics Education, 1: 161-162.

16. Levy B.R., Slade M.D., Gill T.M. 2006. Hearing decline predicted by elders' stereotypes. Journals of gerontology. Series B: Psychological sciences \& social sciences, 61 (2): 82-87.

17. Levy B.R., Slade M.D., Chung P.H. \& Gill T.M. 2015. Resiliency over time of elders' age stereotypes after encountering stressful events. Journal of Gerontology: Psychological Sciences, 70: 886-890.

18. Levy, B., Kosteas, J., Slade, M., \& Myers, L. 2006. Exclusion of elderly persons from health-risk-behavior clinical trials. Preventive Medicine, 43: 80-85.

19. Morganroth Margaret Gullette (2017) Ending Ageism, or How Not to Shoot Old People. Rutgers University Press, 1: 294.

20. Nelson T.D. 2016. Promoting healthy aging by confronting ageism. American Psychologist, 71 (4): 207-221.

21. Ouchida K.M., Lachs M.S. 2015. Not for doctors only: Ageism in healthcare. Generations, 39 (3): $46-57$.

22. Robbins L.A. 2015. The pernicious problem of ageism. Generations, 39 (3): 6-9. 


\section{References}

1. Balabanova K.A. 2017. Jejdzhizm kak otrazhenie otnoshenija $\mathrm{k}$ pozhilym ljudjam $\mathrm{v}$ sovremennom obshhestve: postanovka problemy [Ageism as a reflection of attitudes towards older people in modern society: problem statement]. Cherepoveckie nauchnye chtenija - 2016. Materialy Vserossijskoj nauchno-prakticheskoj konferencii. 1: 11-13.

2. Barsukov V.N. 2016. Population ageing in the context of the demographic transition concept]. Voprosy territorial'nogo razvitiya. 1 (31): 3 (in Russian)

3. Vangorodskaya S.A. 2018. The factors of self-preservation behavior of the population in the region (based on empirical studies). Research result. Sociology and Management, 4 (2): 13-26. (in Russian) DOI: 10.18413/2408-9338-2018-4-2-0-2

4. Vishnevskij A.G. 2015. Vremya demograficheskih peremen: izbr. st. [Time of demographic change: selected articles]. M., Publ. Vysshej shkoly ekonomiki, 517 p.

5. Klupt M.A. 2010. Demograficheskaya povestka XXI veka: teorii i realii [Demographic agenda of the XXI century: theories and realities]. Sociologicheskie issledovaniya, 8(316): 60-71. (in Russian)

6. Kolpina L.V., Ivanov S.V., Kurdjaev S.M., Shhitikova O.B. 2015. Ageizm in elderly people perception and its influence on social health of advanced and senile age population. Vestnik Vserossijskogo obshhestva specialistov po mediko-social'noj jekspertize, reabilitacii i reabilitacionnoj industrii. 4: 74-81. (in Russian)

7. Kolpina L.V., Reutov E.V. 2019. The influence of ageist stereotypes on formation of selflimiting practices of older citizens. Central russian journal of social sciences, 14(2): 32-45. (in Russian) DOI: 10.22394/2071-2367-2019-14-2-32-45

8. Kolpina L.V., Reutova M.N. 2019. Theoretical aspects of the study of the mechanism of selective interiorization of senior citizens' negative gerontostereotypes. Social competence, 4. (2):153161. (in Russian)

9. Mikljaeva A.V. 2014. Contents age stereotypes: an empirical typology. Pis'ma v Jemissija. Offlajn, 2: 2148 URL: http://www.emissia.org/offline/2014/2148.htm (accessed: 09.09. 2020). (in Russian)

10. Reer D. 2014. Economic and social implications of the demographic transition. Demographic review, 1(4): 41-67. (in Russian) URL: https://demreview.hse.ru/issue/view/154/156 (accessed: 09.09. 2020).

11. Smirnova T.V. 2008. Ageing people: stereotypic image and social distance. Sociologicheskie issledovaniya, 8 (292): 49-55. (in Russian)

12. Subetto A.I. 2018. Noosfernaya paradigma strategii voskhodyashchego vosproizvodstva naseleniya Rossii [Noosphere paradigm of the strategy of ascending reproduction of the Russian population]. Uroven' zhizni regionov Rossii. 1(207): 77-94. (in Russian) DOI: https://doi.org/10.24411/1999-9836-2018-10009

13. Allen J.O. 2016. Ageism as a risk factor for chronic disease. The Gerontologist, 56(4): $610-614$.

14. Butler R.N. 1969. Age-ism: Another form of bigotry. The Gerontologist, 9: 243-246

15. Levenson A.J. 1981. Ageism: A major deterrent to the introduction of curricula in aging. Gerontology and Geriatrics Education, 1: 161-162.

16. Levy B.R., Slade M.D., Gill T.M. 2006. Hearing decline predicted by elders' stereotypes. Journals of gerontology. Series B: Psychological sciences \& social sciences, 61 (2): 82-87.

17. Levy B.R., Slade M.D., Chung P.H. \& Gill T.M. 2015. Resiliency over time of elders' age stereotypes after encountering stressful events. Journal of Gerontology: Psychological Sciences, 70: $886-890$.

18. Levy, B., Kosteas, J., Slade, M., \& Myers, L. 2006. Exclusion of elderly persons from health-risk-behavior clinical trials. Preventive Medicine, 43: 80-85.

19. Morganroth Margaret Gullette (2017) Ending Ageism, or How Not to Shoot Old People. Rutgers University Press, 1: 294. 
20. Nelson T.D. 2016. Promoting healthy aging by confronting ageism. American Psychologist, 71 (4): 207-221.

21. Ouchida K.M., Lachs M.S. 2015. Not for doctors only: Ageism in healthcare. Generations, 39 (3): 46-57.

22. Robbins L.A. 2015. The pernicious problem of ageism. Generations, 39 (3): 6-9.

\section{ИНФОРМАЦИЯ ОБ АВТОРАХ}

Колпина Лола Владимировна, кандидат социологических наук, доцент, независимый эксперт, Белгородский государственный национальный исследовательский университет, Белгород, Россия

Бояринова Ирина Владимировна, кандидат социологических наук, доцент кафедры социальных технологий и государственной службы Белгородского государственного национального исследовательского университета, Белгород, Россия

Вангородская Светлана Анатольевна, кандидат социологических наук, доцент кафедры социальных технологий и государственной службы Белгородского государственного национального исследовательского университета, Белгород, Россия

\section{INFORMATION ABOUT THE AUTHORS}

Lola V. Kolpina, candidate of sociological Sciences, associate Professor, Independent Researcher, Belgorod state national research University, Belgorod, Russia

Irina V. Boyarinova, candidate of sociological Sciences, associate Professor of the Department of social technologies and public service, Belgorod state national research University, Belgorod, Russia

Svetlana A. Vangorodskaya, candidate of sociological Sciences, associate Professor of the Department of social technologies and public service Belgorod state national research University, Belgorod, Russia 